\title{
DIMENSÕES FACTUAL E VIRTUAL NO GERENCIAMENTO DA ENFERMEIRA
}

\author{
THE FACTUAL AND VIRTUAL DIMENSIONS OF NURSING \\ PROFESSIONALS MANAGEMENT \\ DIMENSIONES FÁCTICAS Y VIRTUALES EN LA GERENCIA \\ DE LA ENFERMERA
}

\author{
Maria Auxiliadora Trevizan ${ }^{1}$ \\ Isabel Amélia Costa Mendes ${ }^{1}$ \\ Suzel Regina Ribeiro Cury ${ }^{2}$ \\ Neide Fávero ${ }^{1}$ \\ Alessandra Mazzo Caldonha ${ }^{3}$
}

\begin{abstract}
RESUMO: Sob o ângulo da análise histórica, tanto da organização hospitalar como do exercício da enfermagem no contexto burocrático do hospital, constatou-se que a instituição estudada atribui à enfermeira um acervo de funções gerenciais, principalmente do tipo burocrático. Este fato foi verificado através de dados empiricos extraídos do seu desempenho nas unidades de internação, demonstrando que, dentre suas funçōes, as de gerenciamento são privilegiadas naquela instituição. A interpretação que se deu a esses resultados foi a de que no âmbito hospitalar a enfermeira não pode se furtar ao exercício da função gerencial, embora se espere que esse exercício se faça de modo diverso do encontrado. Diante desses fatos, ou seja, dessa dimensão factual, as autoras delineam a dimensão virtual do processo de gerenciamento.
\end{abstract}

PALAVRAS-CHAVE: gerenciamento, enfermeira, hospital

A busca de maior eficiência e competência para os hospitais estimulou a introdução dos princípios da administração científica nessas organizações associados a características do modelo burocrático fornecido por Weber que descreve a burocracia como uma estrutura de organização ideal baseada nos conceitos sociológicos de racionalização das atividades coletivas (Rakich; Longest; O'donovan, 1977).

Sabemos que a abordagem da administração científica fundamenta-se no trabalho de Taylor por ocasião da mudança do século XIX para o século XX. Taylor visava o máximo de produção através do aumento da eficiência, enfatizando a substituição dos métodos empíricos pelos científicos, mesmo nas menores tarefas de cada ofício.

Acompanhando o desenvolvimento da administração, os hospitais americanos foram envolvidos pela ascendência do taylorismo, a começar pelo movimento de padronização hospitalar, eclodido sete anos após a publicação do livro de Taylor. No Brasil, as idéias tayloristas começaram a ser incorporadas nas instituições de saúde a partir da década de 40 , obtendo

\footnotetext{
${ }^{1}$ Professor Titular da Escola de Enfermagem de Ribeirão Preto da Universidade de São Paulo - Centro Colaborador da OMS para o Desenvolvimento da Pesquisa em Enfermagem.

${ }^{2}$ Professora Doutora do Departamento de Enfermagem da Faculdade de Medicina do Triângulo Mineiro.

${ }^{3}$ Doutoranda do Programa de Pós-Graduação em Enfermagem Fundamental da Escola de Enfermagem de Ribeirão Preto da Universidade de São Paulo - Centro Colaborador da OMS para o Desenvolvimento da Pesquisa em Enfermagem. Bolsista do CNPq.
} 
destaque na década de 60 .

Nesse sentido, um fator de marcante influência na evolução da organização hospitalar brasileira foi a introdução dos Princípios Básicos de Padronização Hospitalar em 1944, os quais manifestavam a nítida intenção de implantar a burocratização nessa instituição, bem como atribuir ao médico a supervisão competente e rigorosa do pessoal vinculado aos serviços técnicos tendo em vista a manutenção desse trabalho no mais alto nível de eficiência.

Sobre esta padronização hospitalar MacEachern (1951), em seu relato, enfatiza que nunca antes havia tido um movimento tão difundido para a melhoria dos hospitais, que objetivasse oferecer ao cliente o melhor cuidado profissional e científico. Entende o autor que o crescimento de uma consciência hospitalar talvez seja o ponto que melhor caracterize o progresso havido no século XX no cuidado ao doente. Na sua opinião, as organizações hospitalares e os trabalhadores hospitalares, individualmente, entraram num período de instrospecção, de tentativa de uniformizar seu trabalho em termos de serviço ao cliente. Também para Campos (1952) essa organização dos serviços hospitalares, modelada por um mínimo, originada pela padronização hospitalar, foi uma etapa monumental. Diz ele: "Casou-se admiravelmente com outros três fatores de capital importância no progresso renovador dos nossos dias: a enfermagem, a superintendência e a orientação no planejamento" .

Na descrição dos padrões mínimos para dezesseis setores hospitalares, dentre eles a enfermagem, encontramos itens relacionados à organização, coordenação, supervisão, recursos, pessoal, etc... que demonstram a relevância das funções gerenciais. Ainda há que se considerar que, apesar da intenção manifesta nos princípios básicos mencionados de se atribuir ao médico a supervisão de outros profissionais, os padrões mínimos para alguns setores determinam que sua organização e coordenação devem estar sob a direção de enfermeira competente e com habilidade executiva. Podemos dizer que fica clara a expectativa do médico em relação à enfermeira como um profissional qualificado para gerenciar. $O$ empenho do médico nesse sentido submete e subjuga a enfermeira a oferecer seu apoio no processo de tratamento ao cliente fundamentado, quase que exclusivamente, nas exigências da estrutura formal e nas necessidades do trabalho médico.

Ao analisar a enfermagem no contexto da burocratização hospitalar, Trevizan (1988) relata que desde a sua institucionalização como profissão, esta disciplina também vem recebendo influências de conceitos provenientes da Administração, os quais têm facilitado a sua inserção nas instituições burocráticas. Outro fator relevante para essa adesão está relacionado à reforma no âmbito da enfermagem implementada por Florence Nightingale quando fica evidente seu desejo de transformar as enfermeiras que ocupam cargos administrativos em agentes de mudanças da estrutura hospitalar. É o início da preocupação das enfermeiras com o trabalho hospitalar racionalmente organizado; é o início da burocratização da enfermagem, em consonância com a burocratização hospitalar.

Em síntese, percebemos que as forças propiciatórias da burocratização do trabalho da enfermeira são oriundas de três fontes: da própria enfermagem quando realiza um ideal da reforma sob a iniciativa de Nightingale - a adoção de uma divisão de trabalho; da organização hospitalar - a fusão da função organizacional é uma responsabilidade do administrador, mas este profissional é impedido pela estrutura formal de atuar efetivamente na linha de frente, tornando a enfermeira a representante administrativa da instituição. Mauksch (1966) esclarece que a posição da enfermeira no hospital constitui um demonstrativo deste fato, ou seja, o de

${ }^{4}$ Tais princípios foram estabelecidos pelo Cólegio Americano de Cirurgiöes em 1918. No Brasil, estes princípios foram traduzidos e resumidos por: ALMEIDA, T. - Padrão dos hospitais dos Estados Unidos e o nosso curso. In: Brasil. Ministério da Saúde. Divisão de Organização Hospitalar. Trabalhos publicados pela DOH. Coletânea, vol. 6. Rio de Janeiro, 1964. 
que o papel da enfermeira é profundamente afetado pela sua obrigação de representar a continuidade de tempo e de lugar. Para o autor o fato social e a expectativa geral de presença física contínua e obrigatória entre muitos especialistas transitórios adicionam uma sobrecarga à enfermeira, a de coordenar os que entram e os que saem. Assim sendo, o fato de estar presente reflete a expectativa de que ela mantenha a ordem no fluxo do tráfego e na seqüência de eventos que são esquematizados para o paciente. A terceira força que propicia essa burocratização é proveniente, como já mencionamos, da expectativa médica.

Podemos dizer que, ainda hoje, os pressupostos de Taylor e de Weber têm sido relevantes na orientação para maior eficiência e competência do serviço de enfermagem hospitalar, e que as forças propiciatórias da burocratização do trabalho da enfermeira continuam em vigência, apesar da obsolescência dessas idéias e condutas. Fundamentadas nessas considerações são nossos objetivos: a) configurar a dimensão factual do processo administrativo da enfermeira e b) delinear a dimensão virtual do processo gerencial e de liderança dessa profissional.

\section{DIMENSÃO FACTUAL DO PROCESSO ADMINISTRATIVO DAENFERMEIRA}

Para configurar a dimensão factual do processo administrativo da enfermeira utilizamos como referência as análises efetuadas por Ferreira - Santos; Minzoni (1968), Ferreira-Santos (1973), Trevizan (1978), Trevizan (1988) e Ferraz (1995). Estas investigações foram realizadas em um mesmo hospital-escola e, como pode ser observado, correspondem às décadas de 60 , 70,80 e 90.

Na década de 60, Ferreira-Santos e Minzoni (1968) empreenderam um estudo com a finalidade de investigar como estava sendo distribuído o trabalho de enfermagem em quatro unidades de internação do referido hospital. Dos dados obtidos depreenderam as autoras que foi elevada a porcentagem de tempo utilizado em atividades longe do paciente e, por outro lado, baixa a porcentagem de tempo gasto em atividades diretas pelas enfermeiras. Das atividades indiretas, realizadas por estas profissionais, os valores mais elevados se relacionam à organização em todas as unidades observadas, ou seja, as enfermeiras se envolvem predominantemente com atividades administrativas tendo em vista o bom funcionamento das unidades ou do hospital. Como exemplos de tais atividades citam: distribuição do serviço, organização de papeletas e arquivos, destacando que o nivel não próprio em que a enfermeira mais trabalha é o nível de secretária. Ferreira-Santos e Minzoni (1968) enfatizam em sua análise que suas investigações revelaram um problema crucial para a enfermagem brasileira - cuidado integral do paciente versus enfermeira administradora, pois a realidade observada é muito divergente do ideal pretendido pela profissão. As autoras questionam: " Por que preparar tão bem as enfermeiras se elas não vão cuidar dos pacientes? Para o tipo de atividades que vêm predominantemente executando não estará faltando um Curso de Administração de Empresas?" Salientam que a enfermeira " não pode permitir que a pessoa do doente - razão de ser dos cuidados de enfermagem - seja relegada a plano inferior à administração da unidade"; recomendam ao hospital estudado que propicie "maior aproximação enfermeira-paciente" e que "considere o paciente como centro dos cuidados de enfermagem".

Ferreira-Santos (1973) ao analisar as expectativas dos objetos sociais mais relevantes que interagem com a enfermeira observou que os elementos da administração hospitalar esperam que essa profissional seja eficiente, em outros termos, "essa eficiência é satisfatória quando o funcionário é pontual, não falta muito ao serviço e respeita as linhas gerais de autoridade da instituição". As expectativas em relação ao desempenho profissional da enfermeira, por parte da administração do serviço de enfermagem do hospital estudado são: "a) execute a contento as tarefas inerentes á chefia da unidade de enfermagem, incluindo distribuição do pessoal de enfermagem pelas diferentes enfermarias e serviços, manutenção de bom relacionamento com os médicos e com o pessoal de enfermagem e cuidado dos doentes; b) aceite as situações 
decorrentes da escassez de enfermeiras que se refletem na instabilidade e descontinuidade com mudanças freqüentes de local e nos horários de trabalho". Os médicos desejam das enfermeiras o exercicio da enfermagem científica com a garantia de total segurança dos pacientes. Esperam que os pacientes "estejam preparados para condições ótimas de ensino e que as enfermeiras colaborem nos seus trabalhos de pesquisa". A expectativa do médico quanto ao seu relacionamento com a enfermeira é dúbia: por um lado, reconhece seu preparo e capacitação, e dela espera a iniciativa e independência no exercício da enfermagem; por outro lado, espera submissão, respeito e disciplina. Ao investigar as tarefas realizadas pela enfermagem, a referida autora verificou que as enfermeiras têm se dedicado principalmente às tarefas de organização do serviço de enfermagem e de sua sintonia com os demais serviços hospitalares, buscando assegurar o funcionamento eficiente da instituição visando suas finalidades. Do exame da situação real, Ferreira-Santos (1973) argumenta que "as enfermeiras, pressionadas por elementos adversos da situação (escassez de pessoal e de equipamento, objetos sociais frustradores), refugiaramse em atividades predominantemente administrativas...Desistindo de obter gratificação no trato direto do paciente, refugiam-se em comportamentos de supervisores e administradores, delegando a maioria das funções básicas e técnicas para o pessoal das categorias inferiores da equipe de enfermagem". Para esta autora, as enfermeiras legitimam esse comportamento apoiadas nas ideologias das escolas de enfermagem do país "e na situação concreta de carência de pessoal qualificado no hospital em foco". Entretanto, conforme assevera, este comportamento é ambivalente uma vez que as enfermeiras, sujeitos do mesmo estudo, afirmam que sua tarefa primordial é o cuidado integral e direto ao paciente.

Ainda na década de 70, Trevizan (1978) ao estudar em dois periodos de tempo - $1973 \mathrm{e}$ 1976 - as atividades dos enfermeiros-chefes de unidades de internação do mencionado hospital, verificou a evolução das atividades administrativas, de assistência direta ao paciente, de colaboração no ensino e na pesquisa, que devem ser delegadas ao pessoal auxiliar, que devem ser executadas por pessoas de outros serviços e particulares. Das conclusões da autora salientamos que "a maioria das atividades executadas pelos enfermeiros-chefes não condiz com o que é esperado destes profissionais ... a porcentagem mais alta de tempo gasto, pelos enfermeiros-chefes no desempenho de suas atribuições, se relaciona às atividades administrativas, principalmente as de caráter burocrático". Em 1973, a média de tempo gasto nestas atividades foi $38,90 \%$ e em 1976,53,15\%. Quanto às atividades de assistência direta ao cliente, foi verificado que a média de tempo gasto, nos dois períodos, pelos enfermeiros-chefes em tais atividades foi $11,61 \%$, ou seja, $9,26 \%$ em 1973 e 13,96\% em 1976 . Trevizan (1978) constatou que $40 \%$ dos enfermeiros investigados consideram que essa atividade pode ser delegada ao pessoal auxiliar; entretanto, $70 \%$ dos enfermeiros referiram insatisfação no trabalho, sendo a falta de tempo para se dedicarem às atividades de assistência direta indicada como um dos motivos desta insatisfação.

Ao abordar sobre a gestão administrativa da enfermagem integral nos serviços de saúde, Ribeiro (1971) advogava que a assistência integral de enfermagem deve manter sempre um nivel razoável de trabalho direto executado pela própria enfermeira, pois o contato com o grupo de pacientes é essencial para seu trabalho, seja técnico ou administrativo.

Já na década de 80 , Trevizan (1988) focalizou sua análise na função administrativa da enfermeira buscando averiguar seu comportamento gerencial segundo o critério das imposições do processo organizacional de uma instituição hospitalar burocrática. Desta forma, a autora estabeleceu uma tipologia das funções administrativas burocráticas e não-burocráticas, a qual alicerçou a classificação destas funções exercidas por enfermeiras de quatro unidades de internação do referido hospital-escola, durante o período de 1973 a 1985; portanto, os resultados e as conclusões obtidas pela autora retratam o equivalente a treze anos de investigação realizada em quatro etapas. Do estudo depreende-se que as funçōes administrativas burocráticas perfazem $74 \%$ do total de funções administrativas, sem variações estatisticamente significativas entre 
unidades ou entre anos. Este resultado indica uma tendência para a rotinização e impessoalidade e, portanto, vinculação mais acentuada a normas preestabelecidas. O tipo de função burocrática mais desenvolvida pelas enfermeiras corresponde à expectativa médica, enquanto que o tipo de função que em segundo lugar recebe maior dedicação dessa profissional corresponde à expectativa da organização hospitalar. Entretanto, a função burocrática que recebe menos atenção da enfermeira emana de expectativa do próprio serviço de enfermagem.

Decorridos oito anos dos resultados encontrados por Trevizan (1988), Deienno (1993) analisou as atividades administrativas burocráticas e não-burocráticas realizadas por enfermeiras de unidades de internação de um hospital de ensino de um município do Estado de Minas Gerais. Sua análise foi fundamentada na tipologia das funções administrativas burocráticas e no conceito de função administrativa não-burocrática estabelecidos por Trevizan (1988). As conclusões de Deienno (1993) evidenciam que as enfermeiras investigadas dispenderam aproximadamente $53 \%$ de seu tempo em atividades administrativas burocráticas e $11 \%$ em não burocráticas; demonstram também que cerca de $17 \%$ do tempo destas profissionais foi dedicado às atividades de assistência direta ao paciente.

Teoricamente tem sido apregoado que a enfermeira deve dedicar-se à assistência direta aos pacientes e fazer dela o seu objeto de trabalho. Esta aspiração está refletida nas atribuições determinadas a essa profissional pelo manual da Divisão de Enfermagem da instituição estudada; não obstante, conforme ficou demonstrado, a enfermeira desse hospital não chega a dedicar um quinto de seu tempo a essas funções. Segundo Trevizan (1988), " a prática nos demonstra que a enfermeira atinge o paciente por meio de funções administrativas, ou que ela se perde no próprio exercício dessas mesmas funções". A atuação administrativa da enfermeira tem beneficiado quase que somente a organização, em detrimento do desenvolvimento de valores profissionais. É preciso corrigir esta atuação e configurar uma nova dimensão do processo gerencial da enfermeira. A autora entende que esta nova dimensão gerencial deve ser alicerçada na assistência ao cliente.

Na década de 90, Ferraz (1995) descreveu e analisou a forma da administração em enfermagem exercida no hospital universitário em questão, com a perspectiva de fornecer pistas para sugerir um reordenamento da atividade administrativa da enfermeira. A autora reconhece que a enfermeira brasileira ainda centraliza suas atividades na área administrativa burocrática e afirma que o cenário encontrado e analisado por Trevizan (1988) não se alterou, ou seja, "a prática dos enfermeiros em instituições de saúde privilegia o gerenciamento de unidades de serviços e, desta forma, estes profissionais têm realizado uma administração em enfermagem prioritariamente voltada para a tecnoburocracia hospitalar".

Através da reflexão e análise de depoimentos dos atores sociais participantes da investigação, Ferraz (1995) aponta suas inquietações em relação a vários aspectos tanto da administração superior como da administração intermediária da enfermagem. Por parte da Divisão de Enfermagem há o reconhecimento do distanciamento do enfermeiro do cuidado e em suas argumentações a autora observou que essa administração superior "não tem tratado o cuidado ao doente, enquanto objeto de trabalho da sua esfera de atuação, limitando-se a pontuá-lo como de responsabilidade dos diretores de serviço". Por sua vez, os depoimentos obtidos acerca da administração intermediária, ou seja, daquela realizada nas unidades de internação, indicam o envolvimento das enfermeiras com questōes burocráticas provocadas muito mais por ordens externas do que internas à enfermagem. Concordamos com Ferraz (1995) quando enfatiza que os enfermeiros situam-se como gerentes das unidades de intemaçăo, responsabilizandose pela organização do trabalho da enfermagem segundo a lógica do controle técnico e social. Os enfermeiros mais próximos da função assistencial realizam um gerenciamento científico enfatizando o controle mecânico de uma prática desenvolvida por outros agentes. A autora argumenta que "é angustiante ver o profissional enfermeiro envolvido com atividades tão vazias de conteúdos de enfermagem" e relata que os dados de maior impacto fomecidos pelos sujeitos 
de sua investigação apontam para a necessidade de transformações na prática assistencial e gerencial do enfermeiro, o qual está sendo requerido a compartilhar de ações preponderantemente orientadas para o cliente.

Do exposto, acreditamos ter configurado a dimensão factual da administração exercida pela enfermeira. Como explicitamos, esta configuração foi alicerçada em análises realizadas nas décadas de 60 a 90 , em um hospital escola. Entretanto, fundamentadas na nossa experiência profissional de pesquisadoras sobre o tema em questão e no intercâmbio com colegas da prática assistencial e da academia, podemos dizer que o processo administrativo aqui retratado é, de modo geral, desempenhado pelos enfermeiros brasileiros, os quais têm reproduzido o espirito da gerência científica, técnica e manipuladora em consonância com o desenvolvimento da racionalidade instrumental presente na modernidade.

\section{DELINEANDO A DIMENSÃO VIRTUAL DO PROCESSO GERENCIAL E DE LIDERANÇA DA ENFERMEIRA}

A caminho do terceiro milênio, com a invasão da pós-modernidade afetando as ciências, a tecnologia, as artes, o pensamento, o social e o individual, um novo ambiente e uma nova condição para o homem começaram a ser delineados. $\mathrm{O}$ ambiente pós-moderno retrata a dominação da tecnologia eletrônica no cotidiano, com a saturação de informações, diversões e serviços. No contexto da economia, representa o consumo personalizado, seduzindo o individuo para sua moral hedonista, ou seja, busca a sedução do homem através de valores alicerçados no prazer de utilizar bens e serviços. A condição pós-moderna reflete a dificuldade do indivíduo sentir e representar para si próprio o mundo onde vive, pois nada tem identidade definida (Santos, 1993). "A sensação é de irrealidade, com vazio e confusão....ausência de valores e de sentido para a vida. Sem identidade, hierarquias no chão, estilos misturados...o pós-modernismo continua a flutuar no indecidivel. Na condição pós-moderna, a vida não é um problema a ser resolvido, mas experiência em série para se fazer" (Santos, 1993).

A pós-modernidade ainda está nebulosa em nosso meio, mas já invadiu as sociedades desenvolvidas e fundamentalmente vinculadas à nova era, a Era da Informação, na qual conhecimento e informação são fontes essenciais, valiosas e poderosas para gerar riqueza.

Estas perspectivas apontadas trazem, então, uma mudança de paradigma para as organizações. Como instituições representativas de uma era, as organizaçōes de países desenvolvidos passaram a sofrer transformaçōes, ou melhor, verdadeiras revoluçōes pavimentadas pela globalização, pela dominação da tecnologia da informação, pelo desmoronamento da estrutura hierárquica, pelos downsizings e, agora também, pela atenção à necessidade do homem de dar um sentido a sua vida e assim reencontrar sua humanidade.

No caso brasileiro, as fronteiras institucionais precisam se tornar mais porosas para que as organizações se preparem e se capacitem visando a implementação das mudanças exigidas pelo novo contexto mundial e, desta forma, se adaptarem à nova ordem que, no dizer de Stewart (1998), " não são meras tendências, mas fruto de forças poderosas e incontroláveis..."

Ao hospital, organização prestadora de serviços de saúde, também compete esta tarefa se quiser e estiver disposto a se comprometer com os novos anseios. Nesta instituição particularmente interessa-nos delinear a dimensão virtual do processo gerencial e de liderança da enfermeira.

Ferraz (1995) aponta para "a necessidade de iniciarmos uma metamorfose da enfermagem universitária, tomando por base o paradigma ético-estético da pós-modernidade".

Ao tratar do gerenciamento do enfermeiro na assistência ao cliente à luz de novas perspectivas, Fávero (1996) indica alternativas para transformação dessa gerência que, no seu entender, deve ser apoiada em valores mais flexiveis, inovadores e humanos. Para a autora esse processo de transformação decorrerá, dentre outros aspectos, da integração de novos 
conhecimentos.

Ferraz (1997) também argumenta que na gerência flexivel o trabalho estará fundamentado no conhecimento, o que constitui um grande desafio se considerarmos a produção científica, tecnológica e humanitária deste final de século.

Considerando que a informação e o conhecimento são os principais ingredientes da organização da contemporaneidade, compreendemos, conforme argumenta Stewart (1998), que gerenciá-los tornou-se a tarefa mais importante dos individuos que passam a depender de novas habilidades.

Partindo da premissa de que "as pessoas são nosso ativo mais importante", o referido autor enfatiza a importância do capital humano, do capital estrutural e do capital do cliente que, integrados, constituem os ativos do conhecimento, ou melhor, do capital intelectual de uma organização. Para Stewart (1998), o capital humano é a fonte de inovação e renovação; contudo "indivíduos inteligentes não são sinônimo de empresas inteligentes". Desta forma, o capital estrutural significa a alavancagem do conhecimento, seu compartilhamento e sua transmissão entre as pessoas, através de ativos intelectuais estruturais como sistemas de informação, banco de dados, boa gerência, dentre outros, que "transformam o know-how individual em propriedade de um grupo". O capital do cliente significa o valor dos relacionamentos de uma organização com seus clientes.

Nas organizações de enfermagem, argumenta Ferraz (1997), o cuidado é simultaneamente produzido e consumido, favorecendo e conciliando a utilização instrumental do conhecimento, da informação e da experiência do pessoal auxiliar e da enfermeira.

Desta forma, entendemos que tais organizações representam campo fértil para que seus integrantes se tornem trabalhadores do conhecimento e as enfermeiras, gerentes e líderes comprometidas com o desenvolvimento do capital humano, do capital estrutural e do capital do cliente, os quais constituem, em potencial, o capital intelectual da organização de enfermagem.

Neste sentido, Stewart (1998) enfatiza a necessidade de estimular o trabalho em equipe e outras formas sociais de aprendizado para desenvolver o capital humano que passa a compartilhar talento e conhecimento. Considera que as melhores estruturas são as que apresentam menos obstáculos e, portanto, maior trânsito e que permitem, o quanto possível, o trabalho aliado a seus clientes.

Contemplando a dimensão virtual do processo de liderança da enfermeira, analisamos as expectativas do pessoal auxiliar de enfermagem em relação ao comportamento daquela profissional, investigadas por Trevizan (1993). Os resultados encontrados pela autora indicaram que os sujeitos da pesquisa desejam um enfermeiro-líder que busque resultados ótimos e que procure desenvolver a consciência de interdependência, tornando comum o interesse pelos objetivos do serviço; um enfermeiro que valorize e implemente as decisões criativas tomadas em equipe; um enfermeiro que constantemente se envolva com novos conhecimentos, estimulando também nos liderados esta conduta para atualização. Em síntese, desejam ser liderados por enfermeiros que imprimam em sua organização o trabalho em equipe. Os achados de Trevizan (1993) permitem dizer que as expectativas do pessoal auxiliar em relação à liderança do enfermeiro encontram eco nas propostas gerenciais e de liderança do paradigma contemporâneo.

Enfim, e sobretudo, o exercício gerencial e de liderança da enfermeira que almejamos encontra nos valores humanos uma dimensão essencial. As ações de enfermagem permeadas pela excelência, pelo espírito empreendedor, pela confiança, pelo pluralismo, pelo respeito, pela solidariedade e pela generosidade conduzem o trabalhador e seu cliente a um patamar de vida mais saudável, principalmente no que afeta à satisfação de suas necessidades mais interiores.

ABSTRACT: Through an historical analysis of the hospital organization as well as of nursing practice in the bureaucratic context of hospitals, authors found that the studied institution delegates to nurses 
several management functions, mainly bureaucratic ones. This was verified through empirical data about nurse's role in the units, demonstrating that, among her functions, the management ones are privileged in that institution. Results showed that in the hospital field, nurses can not avoid the management function, although there is an expectation of a different management role than the one normally found. Considering this factual dimension, authors also analyse the virtual dimension of this process, in order to investigate the expectations of the nursing personnel regarding nurses' behaviour as managers/leaders. Authors conclude the study demonstrating the importance of the conciliation of the factual-virtual duality in female nurse's management and leadership.

KEYWORDS: management, nurses, hospital

RESUMEN: Sobre el ángulo del análisis histórico, tanto de la organización hospitalaria como del ejercicio de la enfermería en el contexto burocrático del hospital, se constató que la institución estudiada atribuye a enfermeria una cantidad de funciones gerenciales, principalmente de tipo burocrático. Este hecho fue verificado a través de datos empiricos extraídos de su desempeño en las unidades de hospitalización, demostrando que, dentro de sus funciones, las de gerencia son privilegiadas en aquella institución. La interpretación que se dio a estos resultados fue la de que en el ámbito hospitalario la enfermera no se puede alejar del ejercicio de la función gerencial, a pesar de que se espera que ese ejercicio se haga de modo diferente al encontrado. Frente a estos hechos, - sea, frente a esa dimensión fáctica, las autoras delinean la dimensión virtual del proceso de gerencia.

PALABRAS CLAVE: gerencia, enfermera, hospital

\section{REFERÊNCIAS BIBLIOGRÁFICAS}

CAMPOS, E.S. História dos hospitais. In: BRASIL. Terceiro Instituto Internacional de Organizaçăo e Administração de Hospitais. Organização Mundial da Saúde, publicação $n^{\circ} 268,1952$.

DEIENNO, S.R.R. Atuação do enfermeiro em unidade de internação: enfoque sobre as atividades administrativas burocráticas e não-burocráticas. Ribeirão Preto, 1993.99p.. Dissertação ( Mestrado) - Escola de Enfermagem de Ribeirão Preto, Universidade de São Paulo.

FÁVERO, N. O gerenciamento do enfermeiro na assistência ao paciente hospitalizado.. Ribeirão Preto, 1996. 92 p. Tese (Livre-Docência) - Escola de Enfermagem de Ribeirão Preto - Universidade de São Paulo.

FERRAZ, C.A. A transfiguração da administração em enfermagem - da gerência científica à gerência sensivel. Ribeirão Preto, 1995. 248p. Tese (Doutorado) - Escola de Enfermagem de Ribeirão Preto - Universidade de Săo Paulo.

FERRAZ, C.A. Gerenciamento de enfermagem: do modelo burocrático à administraçăo flexivel. In: SOBRAGEN - Sociedade Brasileira de Gerenciamento em Enfermagem. Caderno de atualização cientifica. Série Medicina \& Saúde. O domínio da transiçăo no gerenciamento de enfermagem . para o século XXI. São Paulo, Frôntis Editorial, 1997, p. 3-15.

FERREIRA-SANTOS, C.A. A enfermagem como profissão: estudo num hospital-escola. São Paulo: Pioneira/EDUSP, 1973.

FERREIRA-SANTOS, C.A.; MINZONI, M.A. Estudo das atividades de enfermagem em quatro unidades de um hospital governamental. Revista Brasileira de Enfermagem., v.21, n.5, p.396-442, out. 1968 .

MACEACHERN, M.T. Hospital organization and management. Chicago: Physicians' Record Co., 1951. 
TREVIZAN, Maria Auxiliadora et al.

MAUKSCH, H.O. The organizational context of nursing practice. In: DAVIS, F. The nursing profession: five sociological essays. New York: John Wiley \& Sons, Inc., 1966.

RAKICH, J.S.; LONGEST, B.B. \& O'DONOVAN, T.R. Managing health care organizations, Philadelphia: W.B. Saunders Company, 1977.

RIBEIRO, C.M. A gestão administrativa da enfermagem integral nos serviços de saúde. Rev. Bras.Enf., v.24, n.(1/2), p.70-100, 1971.

SANTOS, J.F. O que é pós-moderno. 11. ed. Săo Paulo: Brasiliense, 1993.

STEWART, T.A. Capital intelectual. Trad. Ana Beatriz Rodrigues e Priscilla Martins Celeste. Rio de Janeiro: Campus, 1998.

TREVIZAN, M.A. Estudo das atividades dos enfermeiros-chefes de unidades de internação de um hospital-escola. Ribeirão Preto, 1978. 117 p. Dissertação (Mestrado). Escola de Enfermagem de Ribeirão Preto da Universidade de São Paulo.

TREVIZAN, M.A. Enfermagem hospitalar: administração \& burocracia. Brasilia: UnB, 1988.

TREVIZAN, M.A. Liderança do enfermeiro: o ideal e o real no contexto hospitalar. São Paulo: Sarvier, 1993. 